\title{
Publicidade de alimentos: vende-se o quê?
}

\author{
Food advertising: selling what?
}

Publicidad de alimentos: qué se vende?

\section{Recebido: 04/04/2018 \\ Aprovado: 08/09/2018 \\ Publicado: 05/11/2018}

\section{Ana Carolina Aguiar Bloemer ${ }^{1}$ Rosa Wanda Diez Garcia ${ }^{2}$}

O objetivo deste estudo foi analisar os argumentos de persuasão da publicidade de alimentos, relacionadas à emoção e à praticidade, apresentadas em televisão brasileira. Trata-se de um estudo descritivo e exploratório com abordagem qualitativa em que analisou dez exemplos de comerciais que foram selecionados através do acompanhamento de dois canais aberto de por sete dias em períodos sorteados aleatoriamente, no ano de 2017. A análise mostrou que o discurso recorre a argumentos relacionados a solução de problemas da vida cotidiana, associando às demandas de sentimentos que têm na alimentação a oferta de afeto relacionado principalmente a papéis familiares. Os personagens principais são mulheres em contextos familiares ou em circunstâncias comuns da rotina, que expressam pressa ou automatismo das funções na tarefa de preparar a alimentação. 0 alimento é oferecido como solução para as preocupações da vida prática e das frustrações, induzindo o consumo pela promessa de solucionar problemas objetivos e subjetivos.

Descritores: Emoções; Marketing; Publicidade de alimentos.

The aim of this study was to analyze the persuasion arguments of food advertising related to emotion and practicality, in the Brazilian television. This is a descriptive and exploratory study with a qualitative approach in which we analyzed ten examples of commercials that were selected monitoring two open channels for seven days in random periods in the year 2017. The analysis showed that the speech uses arguments related to solving problems of everyday life, associating the demands of feelings to nutrition and giving love, related mainly to family roles. The main characters are women in family contexts or in common, routine conditions that show hurry or automatic functions in the task of preparing food. The food is offered as a solution to the concerns of practical life and frustrations, inducing to consume themwith the promise to solve objective and subjective problems.

Descriptors: Emotions; Marketing; Food publicity.

El objetivo de este estudio fue analizar los argumentos de persuasión de la publicidad de alimentos, relacionadas a la emoción y a la practicidad, presentadas en televisión brasilera. Se trata de un estudio descriptivo y exploratorio con abordaje cualitativo en que analizó diez ejemplos de comerciales que fueron seleccionados a través del acompañamiento de dos canales abiertos por siete días en períodos sorteados aleatoriamente, en el año 2017. El análisis mostró que el discurso recorre a argumentos relacionados a solución de problemas de la vida cotidiana, asociando a las demandas de sentimientos que tiene en la alimentación la oferta de afecto relacionado principalmente a papeles familiares. Los personajes principales son mujeres en contextos familiares o en circunstancias comunes de la rutina, que expresan prisa o automatización de las funciones en la tarea de preparar la alimentación. El alimento es ofrecido como solución para las preocupaciones de la vida práctica y de las frustraciones, induciendo al consumo por la promesa de solucionar problemas objetivos y subjetivos.

Descriptores: Emociones; Mercadeo; Publicidad de alimentos.

1. Nutricionista. Especialista em Nutrição na modalidade Aprimoramento Profissional. Mestre e Doutora em Ciências Médicas. Professora do Curso de Nutrição da Universidade de Ribeirão Preto (UNAERP), Ribeirão Preto, SP, Brasil. ORCID: 0000-0002-8816-9163 E-mail: carolinabloemer@gmail.com

2. Nutricionista. Residência e Especialização em Nutrição. Mestre e Doutora em Psicologia Social. Professora Associada do Curso de Nutrição da Faculdade de Medicina da Universidade de Ribeirão Preto (FMURP-USP), Ribeirão Preto, SP, Brasil. ORCID:0000-0002-7062-974X E-mail: wanda@fmrp.usp.br 


\section{INTRODUÇÃO}

A rotina acelerada do mundo contemporâneo gera problemas que são capitalizados pela indústria, que apresenta uma nova realidade factível de ser comprada e consumida. Dificuldades do cotidiano como a falta de tempo, cuidados com os filhos, com a família, têm na alimentação, um objeto importante no oferecimento de cuidados, afeto, atenção, por meio de alternativas que veiculam todos os atributos necessários, subjetivos e objetivos, na forma de produtos.

Alegrar-se ao perceber o céu claro pela manhã, se entusiasmar ao sentir o aroma de um café fresco, se irritar com o trânsito congestionado, se preocupar com o atraso no trabalho, o medo de assalto, a ansiedade pelo resultado de um exame, o constrangimento de esquecer uma data importante, se magoar com alguma crítica, entre outros, exemplificam a variação de emoções que podem estar presentes no cotidiano. A intensidade e a motivação dessas emoções têm graduações distintas que podem ou não gerar reações e comportamentos ${ }^{1,2}$.

No contexto urbano principalmente, o ritmo de vida está intensificado e as práticas alimentares sofreram com a redução do tempo e da disponibilidade para atividades envolvidas com elas.

O tempo para o planejamento e preparo da comida bem como para as refeições, sempre regularam o ritmo de vida, e estavam em consonância com a divisão do trabalho intrafamiliar sendo que cabia a mulher as responsabilidades relacionadas a essas atividades domiciliares. Como adensamento urbano e a mulher fazendo parte do mercado de trabalho, as práticas alimentares sofreram transformações. Praticidade e agilidade nos procedimentos relacionados ao preparo da comida e ao seu consumo são valorizadas porque está implícito no produto, o trabalho e o tempo ${ }^{3}$.

Estudos que analisaram os dados da Pesquisa de Orçamentos Familiares de diferentes anos, mostram que houve um aumento no consumo de produtos ultraprocessados em ambiente domiciliar ${ }^{4-6}$. Essa problemática é captada pela publicidade e é possível solucionar essas demandas, associá-las a emoções e prazeres, embalados em um produto alimentar.

Atenta à essas transições de valores e estilo de vida de corrente da globalização, a indústria se apoderou dessa situação ofertando uma enorme variedade de alimentos de fácil acesso e rápido consumo vinculados a palavras (slogans), visual (embalagem), gestos (comerciais) e músicas relacionando-os a emoções positivas.

Os fatores ambientais, ideário, a relação custo benefício, exercem influência expressiva, nem sempre associada a palatabilidade do alimento, apesar dos investimentos em alimentos com sabor intensificados.

A quantidade que se consome de um determinado alimento é muito influenciada pelo tamanho da embalagem, além de seu sabor ${ }^{7}$. Estudo mostra que ao dobrar o tamanho da embalagem, os indivíduos consumem cerca de $30 \%$ a mais ${ }^{8,9}$.

Um exemplo clássico para esse dado é o estudo envolvendo a disponibilização de dois tipos de pipocas (boas e velhas) em dois tipos de embalagens (grande e pequenas) em um cinema - o estudo mostrou que a quantidade consumida teve interferência equivalente pelo sabor e pelo tamanho da embalagem ${ }^{10}$. Estudos mostram a correlação entre a disponibilidade de alimento e o seu consumo ${ }^{8,11-14}$. Além disso, relacionar os alimentos com palavras agradáveis também impacta vendas a mais por agregar valor ao produto ${ }^{12}$.

A publicidade de alimentos desenvolveu repertório para "solucionar" essas inúmeras demandas, integrando e associando ensejos subjetivos, que também estão postos nas mudanças ocorridas na vida urbana, e mesmo àqueles existenciais humanos. Por exemplo, 0 conflito que divide a mulher entre trabalhar, $\mathrm{e}$ a maternidade, a falta de tempo para preparar o alimento e dedicar-se à família e ao trabalho, além da forte vinculação do alimento/produto com oferta de expectativas que estão para além do pragmatismo da vida cotidiana, como a felicidade, a realização pessoal, a satisfação na vida amorosa, entre outros ${ }^{15}$. 
Conhecer os argumentos persuasivos de apelos publicitários, particularmente as relacionadas a emoções e praticidade, veiculados na televisão brasileira é o anseio deste ensaio exploratório. Portanto, o objetivo deste estudo foi analisar os argumentos de persuasão da publicidade de alimentos, relacionadas à emoção e à praticidade, apresentadas em televisão brasileira.

\section{MÉTODO}

Trata-se de um estudo descritivo e exploratório, com abordagem qualitativa, com o intuito de conhecer as características e conteúdo de comerciais de alimentos veiculados em três períodos do dia no ano de 2017.

Foram assistidas duas emissoras nacionais e populares (canal aberto), por sete dias cada uma, em três períodos sorteados aleatoriamente ao longo do dia, para seleção destes comerciais.

Os comerciais foram inicialmente gravados, e posteriormente selecionados exemplos por seus apelos envolvendo emoção e praticidade. Dos quais foram selecionados 10 exemplos de comerciais que atendiam ao objetivo do estudo, recorreu-se à análise de conteúdo para o estudo dos argumentos ${ }^{16}$.

Nos procedimentos em que foram assistidos os comerciais, foi realizada a triagem dos melhores exemplos que continham alegações relacionadas ao objetivo do estudo. Nesse processo os pesquisadores elencaram os comerciais que consideraram exemplos apropriados a pesquisa.

Após análise em dupla, por consenso, foram selecionados 10 comerciais e excluídos seis. Os aspectos analisados nos comerciais estudados foram: i) slogan; (mensagens comerciais) ii); personagens envolvidos; iii) contexto social; iv) emoções e sentimentos presentes; v) aspectos motivadores; vi) características visuais e sonoras (cores envolvidas e sonoplastia); vii) menção a características sensoriais; viii) menção aos nutrientes.

\section{RESULTADOS}

Os slogans dos comercias selecionados dizem respeito à valores existenciais ("abra a felicidade"/refrigerante, "o segredo é carinho" /suco, "Para a vida ficar delícia"/margarina); à vitalidade ("energia que dá força /achocolatado, "um q" a mais de disposição" /margarina); à benefícios físicos e emocionais ("você bem por dentro e por fora"/iogurte); à papéis sociais e soluções de dificuldades cotidianas ("light como a vida não é" /macarrão instantâneo; "possibilândia" /biscoito, "você não é você quando está com fome"/chocolate; e relação pais e filhos ("diga sim"/iogurte).

Todas as mensagens apareceram no final do produto. Os detalhes dos comerciais estão apresentados no Quadro 1.

Sobre os personagens envolvidos foi percebido a presença de padrões estéticos atribuídos ao admirado pela sociedade (indivíduos magros de aparência saudável, bem-vestidos e cabelos arrumados) e, majoritariamente, o personagem principal é uma mulher, branca, que se mostra ocupada e preocupada. Algumas dessas mulheres são atrizes brasileiras que são expostas como "mães".

O contexto social envolve especialmente a família ou grupo de amigos, em ambiente doméstico ou em circunstâncias comuns da rotina e, na maioria das vezes, os comerciais expressam a necessidade de que as atividades sejam realizadas em pouco tempo e o caráter mecânico dessas tarefas. Algumas palavras que reforçam essa situação são:

"é rapidinho. vai comendo..."

“...estou atrasada, mãe...",

“... depois a gente lava...".

Pôde-se observar que as emoções e sentimentos expostos pelos personagens são de insatisfação, mal humor, raiva, frustação, cansaço, agitação e preocupação até a realização do consumo do alimento. Trechos como:

"sua vida não é light", "...

8 mulheres ficam mal-humoradas...",

"...você fica insuportável quando está com fome" e "para piorar deixou no vácuo o presidente". 
Quadro 1. Detalhamento dos comerciais analisados. São Paulo, 2017.

\begin{tabular}{|c|c|c|}
\hline Produto & Slogan & Descrição do comercial \\
\hline $\begin{array}{l}\text { Refrigeran } \\
\text { te }\end{array}$ & $\begin{array}{l}\text { Abra a } \\
\text { felicidad } \\
\text { e }\end{array}$ & $\begin{array}{l}\text { Expõe várias situações de personagens com alguma emoção negativa, como mulher } \\
\text { desmotivada no trabalho, briga de casal, garoto com medo de ladrões e a partir do } \\
\text { aparecimento do refrigerante, a mulher se apaixona por um cliente, o casal se beija e } \\
\text { o garoto é salvo. }\end{array}$ \\
\hline $\begin{array}{l}\text { Suco } \\
\text { industriali } \\
\text { zado }\end{array}$ & $\begin{array}{l}\text { O } \\
\text { segredo } \\
\text { é carinho }\end{array}$ & $\begin{array}{l}\text { Mostra uma história de uma mãe na criação de seu filho, com alguns momentos } \\
\text { difíceis, atrasos para buscar no colégio, danificação do urso de pelúcia ao lava-lo, entre } \\
\text { outras situações e no final mostra a mãe sendo a conselheira do filho sobre um amor } \\
\text { mal correspondido. }\end{array}$ \\
\hline Margarina & $\begin{array}{l}\text { Para vida } \\
\text { ficar } \\
\text { delícia }\end{array}$ & $\begin{array}{l}\text { Apresenta um contexto de lanche familiar, o qual a filha diz que está com pressa, mas } \\
\text { a mãe convence a sentar e realizar o lanche em família. }\end{array}$ \\
\hline $\begin{array}{l}\text { Achocolat } \\
\text { ado }\end{array}$ & $\begin{array}{l}\text { Energia } \\
\text { que dá } \\
\text { força }\end{array}$ & $\begin{array}{l}\text { Apresenta a mãe saindo para o trabalho várias vezes e despedindo do seu filho que } \\
\text { está sentado no sofá jogando videogame. Em um certo momento, a mãe percebe que o } \\
\text { filho está apático e então oferecer um achocolatado. A partir desse momento, o filho } \\
\text { fica feliz e vai brincar no campo. }\end{array}$ \\
\hline Chocolate & $\begin{array}{l}\text { Você não } \\
\text { é você } \\
\text { quando } \\
\text { está com } \\
\text { fome }\end{array}$ & $\begin{array}{l}\text { Exibe uma atriz brigando com um grupo de meninos em um vestiário, até que um deles } \\
\text { a aborda dizendo que ela precisa comer um chocolate para melhorar o humor. Assim } \\
\text { que ela consome, elas e transformam um garoto e se mostra mais calma. }\end{array}$ \\
\hline Biscoito & $\begin{array}{l}\text { Possibilâ } \\
\text { ndia }\end{array}$ & $\begin{array}{l}\text { Expõe um homem andando pela rua com vários problemas de corrente ao seu mal } \\
\text { humor e fome. Quando ele encontra o biscoito, ele percebe que é possível fazer tudo } \\
\text { (possibilândia) se consumir aquele biscoito. }\end{array}$ \\
\hline Margarina & $\begin{array}{l}\text { Um "q" a } \\
\text { mais de } \\
\text { disposiçã } \\
\text { o }\end{array}$ & $\begin{array}{l}\text { Retrata o oferecimento de um pão com margarina para vários personagens compressa } \\
\text { e o locutor diz que a marcas e adaptou ao novo ritmo de café da manhã da população } \\
\text { e por isso enriqueceu com mais nutrientes para dar mais disposição ao consumidor. }\end{array}$ \\
\hline Iogurte & $\begin{array}{l}\text { Você } \\
\text { bem por } \\
\text { dentro e } \\
\text { por fora }\end{array}$ & $\begin{array}{l}\text { Exibeumaatrizbrincandocomseufilhoemumparqueecontandoqueomalfuncionamento } \\
\text { dointestinopodelevaraomalhumor, mas que isso pode ser resolvido como consumo do } \\
\text { iogurte. Ela reforça que o consumo do iogurte, portanto pode fazer as pessoas mais } \\
\text { felizes. }\end{array}$ \\
\hline Iogurte & Diga sim & $\begin{array}{l}\text { Mostra várias situações em que os pais precisam dizer "não" para os filhos e no final } \\
\text { estimula os pais a dizerem "sim" quando os filhos pedirem o iogurte, pois eles } \\
\text { diminuíram o teor de açúcar. }\end{array}$ \\
\hline $\begin{array}{l}\text { Macarrão } \\
\text { instantâne } \\
\text { o }\end{array}$ & $\begin{array}{l}\text { Light } \\
\text { como a } \\
\text { vida não } \\
\text { é }\end{array}$ & $\begin{array}{l}\text { Exibe uma mãe com dificuldade em fazer o bebe dormir, demorando horas até que o } \\
\text { marido dela chega e faz barulho acordando a criança. Nesse contexto, o locutor diz que } \\
\text { a vida não é fácil, mas que o macarrão instantâneo pode ajudar. }\end{array}$ \\
\hline
\end{tabular}

Isto pode retratar essas emoções e sentimentos. Após o consumo, essas emoções são imediatamente transformadas para alegria, felicidade, prazer e satisfação.

A mensagem central da maioria dos comerciais é que o consumo do alimento resolverá alguma demanda ou problema que os personagens estão enfrentando, como a falta de tempo, o descontentamento no trabalho, preocupação com filho e mal humor. Isso pode ser exemplificado com algumas das falas dos comerciais, como:

“...só uma coisa que dá jeito...”

"...para aproveitar cada momento"

"tema energia que seu filho precisa" $\mathrm{e}$

"...acho que vou chegar mais tarde...".
E para auxiliar na persuasão dessa mensagem motivadora foram utilizados os recursos sonoros (músicas: Taste The Feeling - Aviicie Conrad Sewell, You got more love thank you know - Chris Jordao, Darrene outras músicas de melodias tranquilizadoras) e recursos visuais (ambientes iluminados, organizados e harmônicos, presença de natureza e personagem com roupas claras).

Com exceção do comercial do macarrão instantâneo, apenas o iogurte e o suco industrializado apresentaram alguma informação sobre nutrientes, no sentido de que havia algo a mais no produto, como a adição de vitaminas e minerais na fórmula. 


\section{DISCUSSÃO}

Quem não quer comprar a "alegria" de um refrigerante em um momento de aflição? $\mathrm{Ou}$ uma sensação prazerosa de estarem lanche com a família, vendida por uma margarina, em um momento de solidão? Ou ter mais disposição para resolver os problemas de trabalho?

Os resultados deste trabalho mostram que a mensagem explicitada pela publicidade de alimentos, em geral, é que estão vendendo um alimento que não vai custar tempo, e que o alimento ainda "dispõe" de uma emoção confortante.

Os estudos mostram que as emoções negativas podem aumentar o consumo alimentar, especialmente de alimentos com alto teor de energia e açúcar ${ }^{17}$. Existem diversas possíveis justificativas para esse aumento de consumo, como a liberação de endorfina e opióides endógenos ao consumir alimentos $^{18}$; a relação das emoções com hormônios reguladores do apetite ${ }^{19}$; e desejar um comportamento aprendido desde a infância.

Baseado nos dados desse estudo, podese afirmar que existe outro fator que colabora para essa associação entre as emoções negativas e consumo alimentar, a persuasão da publicidade de alimentos em fazer os indivíduos acreditarem que o alimento transformará as emoções e sentimentos ruins em bons.

Em estudo prévio ${ }^{20}$, se avaliou a percepção da relação emocional como consumo alimentar através de discursos de mulheres, como observado nos trechos que se seguem:

a) "você tá no ambiente de trabalho, tem uma coisa séria, mas o chocolate me dá força, é como se ele falasse para mim, vai lá que você consegue"; b) "Até a felicidade vai na Coca, porque parece que quando eu tô como sentimento negativo, eu tomo e parece que eu penso: - Vai e encara que você tem peito para isso! E se eu tô feliz, ela me relaxa, ela me fala: - Calma, já deu tudo certo, agora é só curtição! ... a Coca é perfeita em todas as ocasiões e todas as emoções..." c) "Se eu tô brava, eu tenho que comer um chocolate, não adianta ser outro doce... Doce sem geral me deixam felizes, é aquela felicidade instantânea, sabe?".

Os resultados levantados mostram a semelhança entre a história apresentada pelos comerciais, e a características da realidade urbana da população brasileira, como a falta de tempo, as demandas familiares e do trabalho, as preocupações com filhos, o cansaço e frustrações de trabalho.

Essa semelhança usada nos comerciais é uma forte estratégia da publicidade que já foi descrita em outro estudo 21 , como sendo importante para induzir a identificação do consumir a situação apresentada, por isso são utiliza das formas de linguagem, contexto social e valores da população, seduzi-los pela expectativa de soluções de problema e a estimular o sentimento de necessidade de adquirir o produto.

Assim, como em outra pesquisa ${ }^{22}$, o qual analisou publicidade de alimentos em revistas e jornais de circulação no Brasil, os resultados aqui apresentados mostram que o público alvo dos comerciais de alimentos são principalmente mulheres, e estimulam ao consumo.

E, tendo em vista, que todos os alimentos apresentados nos comerciais são alimentos com alto teor energético e rico sem açúcar, estimula-se esse tipo de alimento para resolução de problemas que, consumidos em excesso, podem ser prejudiciais à saúde, agravar doenças crônicas relacionadas com o estado nutricional e excesso de peso.

Foi pouco observado argumentos relacionados a composição de alimentos e quantidades máximas recomendadas de consumo diária, assim como não apresentaram apelos sobre as características sensoriais, relativas ao sabor.

Os apelos se centraram em oferecer emoções e suavizar as tarefas do papel da mulher como provedora de alimento, no sentido físico e metafísico, como oferecer ou consumir o alimento como uma forma de atenção e carinho ("O segredo é carinho, "diga sim", "abra a felicidade") ou uma forma de cumprir apenas sua necessidade biológica ("possibilândia", "você não é você quando está com fome").

0 risco de ganho de peso gerado pelo consumo excessivo dos produtos anunciados pelos comerciais analisados em um cenário de alta prevalência da obesidade ${ }^{23}$, sinalizam a magnitude do problema. 
Neste contexto, comer fora de casa ${ }^{4,24,25}$, onde há uma maior acessibilidade de alimentos; o aumento contínuo das porções e tamanhos das embalagens ${ }^{10,11}$ e o poder da publicidade em afetar as escolhas alimentares dos indivíduos através de manipulações das características externas do alimento, como a embalagem, as descrições do produto e a propaganda 26,27 , são agravantes para o favorecimento desse no consumo de alimentos industrializados, como os processados e ultraprocessados ${ }^{28,29}$.

Combater esse tipo de estratégia de publicidade com uma legislação que coíba abusos publicitários, é uma demanda para compor a pauta de enfrentamento da obesidade pela saúde pública.

\section{CONCLUSÃO}

Apelos publicitários que vinculam demandas sociais e emocionais do consumidor à produtos alimentares, podem ser indutores do aumento do consumo alimentar, funcionando como gatilho para o consumo alimentar contínuo.

Essa constatação deve dar suporte a regulação da publicidade. Nesse sentido, a publicidade de alimentos transcende o direito do cidadão pois o coloca em risco quando utiliza a vulnerabilidade emocional para seduzir o consumidor.

\section{REFERÊNCIAS}

1. Ghisletta P, Nesselroade JR, Featherman DL, Rowe JW. Structure and predictive power of intraindividual variability in health and activity measures. Swiss J Psychol. 2002; 61(2):73-83.

2. Congard A, Dauvier B, Antoine P, Gilles P-Y. Integrating personality, daily life events and emotion: role of anxiety and positive affect in emotion regulation dynamics. J Res Pers. 2011; 45(4):372-84.

3. Louzada MLD, Baraldi LG, Steele EM, Martins APB, Canella DS, Moubarac JC, et al. Consumption of ultra-processed foods and obesity in Brazilian adolescents and adults. Prev Med. 2015; 81:9-15.

4. Bezerra IN, Souza AM, Pereira RA, Sichieri R. Consumo de alimentos fora do domićlío no Brasil. Rev Saúde Publica. 2013; 47(supl1):200-11.

5. Moubarac JC, Martins APB, Claro RM, Levy RB, Cannon G, Monteiro CA. Consumption of ultraprocessed foods and likely impact on human health. Evidence from Canada. Public Health Nutr. 2013; 16(12):2240-8.

6. Claro RM, Baraldi LG, Martins APB, Bandoni DH, Levy RB. Trends in spending on eating away from home in Brazil, 2002-2003 to 2008-2009. Cad Saúde Pública. 2014; 30(7):1418-26.

7. Zlatevska N, Dubelaar C, Holden SS. Sizing up the effect of portion size on consumption: a metaanalytic review. J Mark. 2014; 78(3):140-54.

8. Rolls BJ, Morris EL, Roe LS. Portion size of food affects energy intake in normal-weight and overweight men and women. Am J Clin Nutr. 2002; 76(6):1207-13.

9. Almiron-Roig E, Tsiountsioura M, Lewis HB, Wu J, Solis-Trapala I, Jebb SA. Large portion sizes increase bite size and eating rate in overweight women. Physiol Behav. 2015; 139:297-302.

10. Wansink B, Kim J. Bad popcorn in big buckets: portion size can influence intake as much as taste. J Nutr Educ Behav. 2005; 37(5):242-5.

11. Rolls BJ, Roe LS, Kral TVE, Meengs JS, Wall DE. Increasing the portion size of a packaged snack increases energy intake in men and women. Appetite. 2004; 42(1):63-9.

12. Kral TV, Rolls BJ. Energy density and portion size: their independent and combined effects on energy intake. Physiol Behav. 2004; 82(1):131-8.

13. Flood JE, Roe LS, Rolls BJ. The effect of increased beverage portion size on energy intake at a meal. J Am Diet Assoc. 2006; 106(12):1984-90. 14. Rolls BJ, Roe LS, Meengs JS. The effect of large portion sizes on energy intake is sustained for 11 days. Obesity. 2007; 15(6):1535-43.

15. Diez-Garcia RW. Reflexos da globalização na cultura alimentar : considerações sobre as mudanças na alimentação urbana. Rev Nutr. 2003; 16(4):483-92.

16. Braun V, Clarke V. Using thematic analysis in psychology. Qual Res Psychol. 2006; 3(2):77-101. 17. Van Strien T, Cebolla A, Etchemendy E, Gutierrez-Maldonado J, Ferrer-Garcia M, Botella C, et al. Emotional eating and food intake after sadness and joy. Appetite. 2013; 66(1):20-5.

18. Erlanson-Albertsson C. How palatable food disrupts appetite regulation. Basic Clin Pharmacol Toxicol. 2005; 97(2):61-73.

19. Raspopow K, Abizaid A, Matheson K, Anisman H. Anticipation of a psychosocial stressor differentially influences ghrelin, cortisol and food intake among emotional and non-emotional eaters. Appetite. 2014; 74:35-43.

20. Aguiar-Moreira AC, Diez-Garcia RW. Influência das emoções geradas por eventos de vida no consumo alimentar em mulheres. [dissertação]. Ribeirão Preto, SP: Universidade de São Paulo; 2014. 
21. Burrowes P. Viagem ao território da publicidade. Comunicação, mídias e consumo; 2005; 3(2):205-19.

22. Marins BR, de Araujo IS, Jacob SD. Food advertising: advice or merely stimulation of consumption? Ciênc Saúde Colet. 2011; 16(9):3873-82.

23. Ministério da Saúde (Br). Vigitel Brasil: Vigilância de fatores de risco e proteção para doenças crônicas por inquérito telefônico. Brasília, DF: Ministério da Saúde; 2013. 136 p.

24. Monteiro CA, Levy RB, Claro RM, Ribeiro de Castro IR, Cannon G. Increasing consumption of ultra-processed foods and likely impact on human health: evidence from Brazil. Public Health Nutr. 2011; 14(1):5-13.

25. Levy RB, Claro RM, Mondini L, Schieri R, Monteiro CA. Distribuição regional e socioeconômica da disponibilidade domiciliar de alimentos no Brasil em 2008-2009. Rev Saúde Pública. 2012; 46(1):6-15.
26. Wansink B, Van Ittersum K, Painter JE. How descriptive food names bias sensory perceptions in restaurants. Food Qual Prefer. 2005; 16(5):393400.

27. Costa, CS, Flores TR, Wendt A, Neves RG, Assunção MCF, Santos IF. Comportamento sedentário e consumo de alimentos ultraprocessados entre adolescentes brasileiros: Pesquisa Nacional de Saúde do Escolar (PeNSE), 2015. Cad Saúde Pública. 2018; 34(3):e00021017. 28 Ministério da Saúde (Br). Secretaria de Atenção à Saúde, Departamento de Atenção Básica. Guia alimentar para a população brasileira. 2. ed. Brasília, DF: Ministério da Saúde; 2014. 156 p.

29. Ribeiro H, Jaime PC, Ventura D. Alimentação e sustentabilidade. Estud Av. 2017; 31(89):61-73.

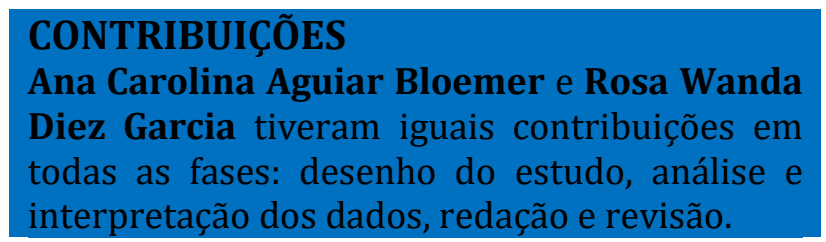

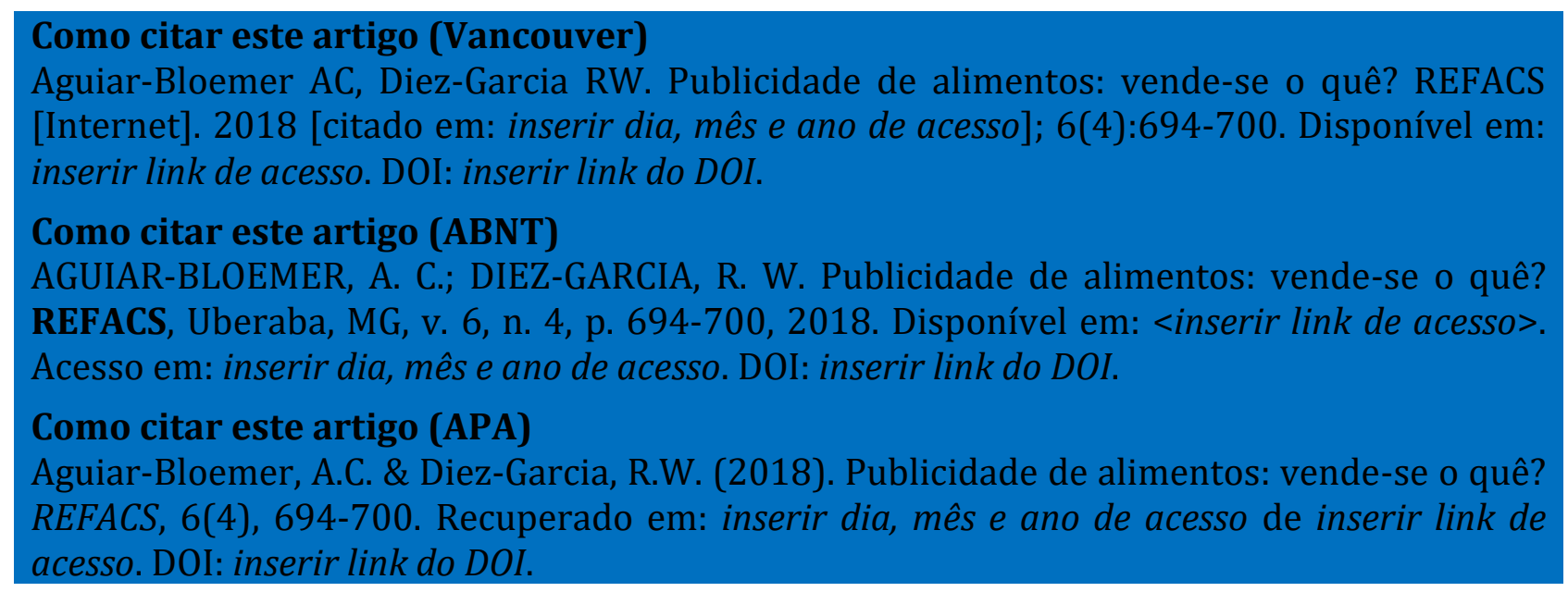

